\title{
Los cien años de Apolinar Díaz Callejas y sus caminos de agua del San Jorge y la Mojana
}

\author{
The hundred years of Apolinar Díaz Callejas and its water roads of \\ San Jorge and Mojana
}
Os cem anos de Apolinar Díaz Callejas e suas estradas aquáticas de San Jorge e Mojana

\author{
Henry Huertas Arrieta ${ }^{1}$ iD \\ Universidad del Norte, Colombia
}

Para citaciones: Huertas, H. (2021). Los cien años de Apolinar Díaz Callejas y sus caminos de agua del San Jorge y la Mojana. El Taller de la Historia, 13(1), 214-232.

Recibido: enero de 2021

Aprobado: mayo 2021

Editor: Sergio Paolo Solano. Universidad de Cartagena-Colombia.
Copyright: (๑) 2021. Huertas, H. Este es un artículo de acceso abierto, distribuido bajo los términos de la licencia https://creativecommons.org/licenses/by-nc-

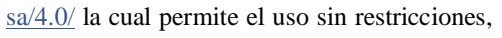
distribución y reproducción en cualquier medio, siempre y cuando que el original, el autor y la fuente sean acreditados.

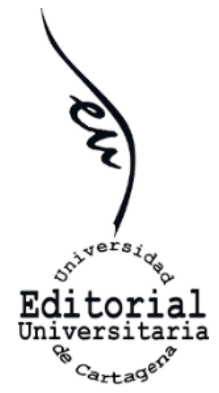

\section{RESUMEN}

Las luchas sociales y políticas que inician con las reformas políticas de los gobiernos liberales en la década del treinta del siglo pasado, fueron caldo de cultivo de los acontecimientos que se van suceder durante los siguientes años del siglo XX en Colombia. Este artículo conmemora los cien años del nacimiento de Apolinar Díaz Callejas, intelectual y político del Caribe colombiano, a partir una reconstrucción histórica de su trasegar en la vida pública como activista sindical y político, y por supuesto, también de su obra. En el aspecto intelectual se resalta su periodo de formación política y de activista sindical y social. Y en la vida política se menciona el rol que desempeñó para implementación de la reforma agraria promulgada en la ley 135 de 1961, en el gobierno de Alberto Lleras Camargo, y que solo pudo concretarse en parte durante el gobierno de Carlos Lleras Restrepo. Todo, gracias al nombramiento de Apolinar en la gobernación de recién creado departamento de Sucre. De igual modo, se resalta las luchas de este intelectual como congresista en defensa de la reforma agraria y de ser vocero de las necesidades de los municipios del sur del departamento de Sucre, ubicados en las regiones del bajo río San Jorge y Mojana, regiones en ese entonces desconocidas para el país.

Palabras clave: Reforma agraria; Mojana; campesinos; terratenientes; inundaciones.

\begin{abstract}
The social and political struggles that began with the political reforms of the liberal governments in the thirties of the last century were the breeding ground for the events that would take place during the following years of the twentieth century in Colombia. This article commemorates the 100th anniversary of the birth of Apolinar Díaz Callejas, intellectual and politician of the Colombian Caribbean, from a historical reconstruction of his public life as a union and political activist, and of course, also of his work. In the intellectual aspect, his period of political formation and as a union and social activist is highlighted. And in political life, mention is made of the role he played in the implementation of

\footnotetext{
Sociólogo, Universidad de Antioquia. Magister Desarrollo Social, Universidad del Norte, Colombia henryhuertasarrieta@gmail.com
} 
the agrarian reform enacted in Law 135 of 1961, during the government of Alberto Lleras Camargo, which could only be partially implemented during the government of Carlos Lleras Restrepo. All thanks to Apolinar's appointment as governor of the newly created department of Sucre. It also highlights the struggles of this intellectual as a congressman in defense of the agrarian reform and to be a spokesman for the needs of the municipalities of the south of the department of Sucre, located in the regions of the lower San Jorge River and Mojana, regions then unknown to the country.

Keywords: Agrarian reform; Mojana; peasants; landowners; floods.

\section{RESUMO}

As lutas sociais e políticas que começam com as reformas políticas dos governos liberais nos anos trinta do século passado, foram um terreno fértil para os eventos que acontecerão durante os anos seguintes do século XX na Colômbia. Este artigo comemora os cem anos do nascimento de Apolinar Díaz Callejas, intelectual e político do Caribe colombiano, a partir de uma reconstrução histórica de seu trasegar na vida pública como sindicalista e ativista político, e, claro, também de seu trabalho. No aspecto intelectual, destaca-se seu período de formação política e como sindicalista e ativista social. E na vida política é mencionado o papel que desempenhou na implementação da reforma agrária promulgada na Lei 135 de 1961, no governo de Alberto Lleras Camargo, e que só pôde ser realizado em parte durante o governo de Carlos Lleras Restrepo. Tudo graças à nomeação de Apolinar no governo do recém-criado departamento de Sucre. Da mesma forma, destaca as lutas desse intelectual como deputado em defesa da reforma agrária e para ser porta-voz das necessidades dos municípios do sul do departamento de Sucre, localizados nas regiões do baixo Rio São Jorge e do Rio Mojana, regiões na época desconhecidas do país.

Palavras-chave: Reforma Agrária; Mojana; camponeses; proprietários de terras; Inundações.

\section{Introducción}

El presente texto no tiene más intención que conmemorar los cien años del nacimiento de Apolinar Díaz Callejas mediante un recuento de su vida y obra, especialmente con lo referente a la implementación de la reforma agraria democrática que se había establecido en la ley 135 de 1961 en el gobierno de Alberto Lleras Camargo, y que solo pudo concretarse tangencialmente más tarde durante el gobierno de Carlos Lleras Restrepo. Todo, gracias al genio y a la gestión del entonces gobernador y senador de Sucre, Apolinar Díaz Callejas. De igual modo, describir el papel crucial que tuvo este intelectual y político para comprender la importancia geográfica, hídrica y ambiental de las subregiones San Jorge y Mojana del departamento de Sucre, y de buscar un punto de sostenibilidad alternativo entre el hombre y el agua, diferente de 
los modelos de desarrollo implementado en el país, impuesto por los organismos internacionales de financiamiento.

\section{Un olvido}

En el segundo semestre del 2021 se cumplen los cien años de los nacimientos de dos grandes intelectuales en el campo de las ciencias sociales, el derecho, las artes y la literatura, no solo del departamento de Sucre sino del país, como lo son: Apolinar Díaz Callejas y Héctor Rojas Herazo. En distancia de sus lugares nacimiento los separa poco menos de cien kilómetros, el primero en Palmito y el segundo en Tolú; igual sucede con el tiempo, pues los separa escasamente menos de dos meses: Díaz Callejas, 22 de junio y Rojas Herazo, 12 de agosto.

Por consiguiente, se conmemora merecidamente el centenario de Héctor Rojas Herazo en el país, y por supuesto, en departamento de Sucre, resaltando su encomiable e invaluables aportes a las artes y a la literatura ${ }^{2}$. Sin embargo, por otro lado, se queda en el olvido el centenario de Apolinar Díaz Callejas. Quien al lado de personajes de la talla de Gerardo Molina, Diego Montaña Cuéllar, Orlando Fals Borda, Eduardo Umaña Luna, Jorge Regueros y tantos otros grandes, hicieron parte de una legión de pioneros que legaron su compromiso con las luchas sociales, políticas, ideológicas e intelectuales que se han dado en Colombia en busca de la transformación social y por hacer realidad ideas progresistas ${ }^{3}$. En ese orden de ideas, surge la pregunta: ¿Cuáles pueden ser las razones de este imperdonable olvido en el departamento y en el país del centenario de Apolinar Díaz Callejas?

Indiscutiblemente puede haber varias respuestas a este interrogante, los cuales pueden encontrarse en el trasegar de la vida misma de este intelectual, en el papel que cumplió en su momento histórico, y en sus posturas y acciones políticas en defensa de una reforma agraria integral y democrática ${ }^{4}$; de igual modo, la defensa de la soberanía colombiana, y por último, en la defensa del Estado social de derecho y de los derechos humanos ${ }^{5}$. Todas estas luchas fueron dadas por Apolinar en un momento histórico álgido para el país, que estaba infestado de Violencia política, exclusiones y sectarismos políticos por parte de bipartidismo del Frente Nacional, éste incubó con mayor fuerza el clientelismo y la corrupción en el sistema político; asimismo, de fuertes conflictos agrarios entre terratenientes y campesinos, el surgimiento de movimientos guerrilleros. Lo internacional no se quedaba atrás, pues la

\footnotetext{
2 Eduardo Márceles Daconte, "Cien años de Héctor Rojas Herazo", en El Magazín Cultural El Espectador. https://www.elespectador.com/el-magazin-cultural/cien-anos-de-hector-rojas-herazo/

${ }^{3}$ Guillermo Segovia Mora, Las batallas de Apolinar. 18 de agosto de 2010. En: https://rebelion.org/las-batallas-de-apolinar/ ${ }^{4}$ La concepción de reforma agraria que tenía Apolinar, entendida "como medio de distribución de ingreso, redistribuyendo la propiedad que lo genera, y de ampliación y consolidación de la base democrática y política en campo". Apolinar Diaz Callejas, De la situación de la nación y del partido liberal, Bogotá, CLAC Impresores Editores, 1977, p. 20.

${ }^{5} \mathrm{La}$ lucha por la defensa de los derechos humanos, le produjo a Apolinar Díaz Callejas amenazas de muerte, una de ella fue la "lista negra" que fue hallada en la ropa de Héctor Abad Gómez tras su asesinato, en 1987. En esa lista reseñan a Apolinar como: "Abogado, dirigente Comité de Derechos Humanos. Apologista de las ideas subversivas en la prensa. Agente del comunismo soviético en el Partido Liberal". En: https://www.elespectador.com/judicial/la-lista-de-sentenciados-por-las$\underline{\text { ffmm-hallada-en-el-bolsillo-de-hector-abad-gomez-article-868962/ }}$
} 
Guerra Fría, la revolución China y cubana, la intervención de Estados Unidos en Latinoamérica, las dictaduras militares del Cono Sur, fueron razones suficientes para que un intelectual de esta categoría entrara a la acción política, pero desde las mismas posibilidades que ofrecía el anquilosado sistema político colombiano, que contaba con una democracia exigua y restringida en esos momentos.

Estas luchas de Apolinar Díaz Callejas resultaron incómodas en un país que había vivido periodos fuertes de violencia política, y que se habían iniciado a partir de la promulgación de la reforma agraria de Alfonso López Pumarejo, ley 200 de $1936^{6}$. López Pumarejo citado por Díaz Callejas, mencionaba, "No, el problema no es que haya invasiones de tierra, habrá invasiones de tierras mientras el campesino no tenga donde trabajar la tierra. La tierra es del que la trabaja y el que no la trabaja después de cierto tiempo pierde sus derechos y la tierra vuelve al estado"7.

Luego, la violencia política es desatada brutalmente con el asesinato de Jorge Eliécer Gaitán en 1948, y se amaina en la dictadura de Rojas Pinilla y a comienzo del Frente Nacional.

Por esos años, si una persona tenía puesta una corbata, la mataban porque era liberal, o porque se suponía que era liberal. Esa violencia fue terrorífica. La violencia conservadora contra el partido liberal comenzó en 1946, y se acabó en gran parte con la formación del Frente Nacional. La violencia fue feroz, feroz. Cobró entre doscientas y trescientas mil muertes ${ }^{8}$.

También estas luchas de este intelectual resultaron incómodas en un departamento que fue creado por el poder político de los latifundistas de Sucre, y que aún hoy lo mantienen; de modo, que celebrarlo desde la institucionalidad política, es dar paso para que estos temas no resueltos y tratados en la obra de Apolinar Díaz Callejas, vuelvan a renacer y a justificarse.

Y se creó un departamento [Sucre] igual a como crearon el del Chocó. Todos estos nuevos departamentos los manejaban los políticos, que en gran parte eran terratenientes. Allá los políticos eran terratenientes, eran dueños de tierras, dueños del poder económico y dueños del poder político.

\footnotetext{
${ }^{6}$ Antonio Posada citado por Fals Borda en su libro Campesinos de los Andes, (Bogotá, Editorial Iqueima. 1961) menciona que: "Según la ley 200 de 30 de diciembre de 1936, ensayo revolucionario de la legislación encaminada a hacer frente al problema agrario en Colombia, el único título válido sobre la tierra es su utilización económica. Por eso los propietarios de la tierra se preocupan por la manera en que sus concertados y hasta sus arrendatarios utilizan la tierra. Esta ley concedió un plazo de gracia de diez años a los hacendados y agricultores para demostrar que realmente utilizaban sus tierras en sentido económico. Cuando en 1947 llegó el momento de examinar nuevamente la situación, el gobierno decidió posponer la vigencia de esta legislación por otros cinco años más. Después, con el advenimiento de la época de la violencia desde 1948 , la aplicación de esta ley ha sido impedida gradualmente. Leyes sucesivas aclararon lo referente a sistemas de arrendamiento, colonización y parcelación de tierras, pero el efecto general de esta legislación ha sido prácticamente nugatorio. En realidad, los vacíos de la ley han permitido a los propietarios aumentar sus propiedades ociosas, estas leyes parecen haber consolidado el dominio actual, lo que no parecía constituir su intención originaria" p. 84.

${ }^{7}$ Ivanov Russi Urbano, El pasado, el presente y futuro visto por Apolinar Díaz Callejas, Bogotá, Editorial Gente Nueva, 2003 , p. 40.

${ }^{8}$ I. Russi Urbano, El pasado, el presente y futuro visto por Apolinar Díaz Callejas, p. 17.
} 
Crearon ese departamento y nombraron un primer gobernador que duró cuatro meses?.

El distanciamiento político y personal de Apolinar de las mañas y triquiñuelas de los políticos de los partidos tradicionales del departamento de Sucre, lo hicieron parecer "antipático" y "repelente". Su modo de ser y actuar no toleraba de ninguna forma actos de corrupción e intromisiones de políticos en sus decisiones de gobierno, estas tenían como propósitos, en su mayoría, favorecer los intereses personales y clientelistas de ellos. De esta manera lo describe Benjamín Herazo Acuña:

Ha sido considerado uno de los Gobernadores de Sucre más serios, estrictos y trabajadores; distante del típico politiquero folklórico, motivo por el cual se ganó injustificadamente la fama de antipático o como decimos en la región, de repelente.

Lo anterior no concuerda con la verdadera condición y calidad humana, intelectual y moral del doctor Apolinar Díaz Callejas, un insigne trabajador y estudioso no solo de la situación nacional sino de la Latinoamericana, hasta el punto que ha presidido asociaciones nacionales e internacionales en defensa de los intereses de las clases menos favorecidas del hemisferio ${ }^{10}$.

\section{Un día después del solsticio de verano y las luchas sindicales}

Un día después de solsticio de verano (22 de junio) de 1921, nace Apolinar Díaz Callejas en Palmito, Sucre, en ese entonces perteneciente al departamento de Bolívar, pues el departamento de Sucre se crearía 45 años después. Sin embargo, en todas sus semblanzas y datos biográficos aparece que nació en Colosó, "pueblo montado en la cúspide de una loma ${ }^{11 " . ~ S e g u ́ n ~}$ Apolinar: "al año ó año y medio de nacer nos fuimos para Colosó. Me crié en Colosó, en la atmósfera y en el ambiente de Colosó ${ }^{12}$ ”.

Colosó -Onné Colosó, primer y único nombre ${ }^{13}$-, es un pueblo antiquísimo su existencia se remonta a los tiempos prehispánicos, que luego en el trascurso de los años y con la extinción de la población indígena del territorio, se fue formando un pueblo de españoles blancos pobres: "A Colosó se fue la parte más pobre de los españoles. La población es de porcentaje blanco y el resto es de mestizos" "14. Colosó fue también escenario en la Colonia del caso de Baltazar Pérez, "indio natural del pueblo de San Miguel de Colosó", que interpuso un recurso de tutela ante la Real Audiencia de Santa Fe de Bogotá en 1675, y fallado años después a su favor en 1685, convirtiéndose en el primer hispanoamericano que se le ampara su derecho humano fundamental de poder contratar libremente su trabajo y se le reconociera su libertad, y la

\footnotetext{
${ }^{9}$ I. Russi Urbano, El pasado, el presente y futuro visto por Apolinar Díaz Callejas, p. 26.

${ }^{10}$ Benjamín Herazo Acuña, Semblanzas de hombres meritorios, Bogotá, Ecoe, 1994, p. 115

${ }^{11}$ I. Russi Urbano, El pasado, el presente y futuro visto por Apolinar Díaz Callejas, p. 9.

${ }^{12}$ I. Russi Urbano, El pasado, el presente y futuro visto por Apolinar Díaz Callejas, p. 9.

${ }^{13}$ Apolinar Díaz Callejas, "Rosa Luisa Uribarren", en Apolinar Díaz Callejas, Ensayos, Narraciones y Crónicas de Colosó, Bogotá, Plaza Impresores, 1998, p. 25.

${ }^{14}$ I. Russi Urbano. El pasado, el presente y futuro visto por Apolinar Díaz Callejas, p. 9.
} 
de su mujer e hijos, para "servir a quien quisiere e fuere de su voluntad, mejor se lo pagara y más buen trata le hiziere" 15 .

Más tarde, en la primera mitad del siglo XIX y en las primeras décadas del siglo XX, Colosó tuvo un crecimiento económico importante por el auge de las exportaciones de materia prima del país, especialmente por el tabaco, algodón, cacao y "el bálsamo de Tolú", estos productos eran cultivados en la región de los Montes de María. Esta bonanza económica propicia la llegada de extranjeros a Colosó, como: italianos, alemanes, españoles y siriolibaneses (mal llamados turcos), en busca de oportunidades de negocios, ofrecidas por boom de las exportaciones.

La presión sobre la tierra en Colosó producida por las exportaciones de estos agroproductos y del aumento de las migraciones internas y externas, desataron conflictos agrarios, ante tal situación, en 1913 se funda en Colosó el primer "sindicato agrario de Colombia", fundado por antioqueño Eduardo Arango y Córdoba, que buscaba a través del sindicato la defensa de los campesinos pobres de los terratenientes de zona y de los comercializadores de las materias primas de exportación. Sin embargo, los conflictos por la tierra seguirían siendo una constante en Colosó, y fueron precisamente estas luchas agrarias de los campesinos vista de cerca desde la infancia y la juventud de Apolinar Díaz callejas, las que fueron nutriendo su educación política y sentimental, y determinado su "manera de ser":

[Colosó] Fue un pueblo donde jamás faltaron los conflictos agrarios. Desde que yo estaba pequeño en la escuela de Colosó había conflictos agrarios y presos, de manera que la cuestión agraria y de la tierra estuvo en mi mente desde que nací. Este ambiente determinó mi manera de ser. Por eso digo que desde esa época fui izquierdista, desde esa época salí con el tema agrario en la cabeza. Y así, cuando llegué a Cartagena y Barranquilla a estudiar, llevaba esa formación de modo inconsciente, natural, de ciertos temas ideológicos. Por eso para mí no fue difícil ponerme a leer cosas del socialismo, del antifascismo. Nada de eso me fue difícil, porque estaba en la atmósfera que se vivía en Colosó ${ }^{16}$.

Esta formación política inicial de Apolinar Díaz Callejas fue fortalecida durante su formación académica inicial y profesional, primero en Barranquilla y luego en Cartagena. Además, el contexto político nacional e internacional fue crucial para su formación ideológica, en lo nacional el partido liberal estaba en el poder después de cincuenta años de hegemonía conservadora (1880-1930), y había empezado hacer reformas políticas y sociales importantes, en los gobiernos de Enrique Olaya Herrera y de Alfonso López Pumarejo, especialmente, la reforma agraria de 1936. En plano internacional, el acceso de los fascismos en Europa, como: fascismo en Italia, el Nazismo en Alemania y el falangismo en España, que causaría la Guerra Civil Española:

${ }^{15}$ Apolinar Díaz Callejas, "Baltazar Pérez: precursor del recurso de tutela", en Ensayos, Narraciones y Crónicas de Colosó, pp. 103-104.

${ }^{16}$ I. Russi Urbano, El pasado, el presente y futuro visto por Apolinar Díaz Callejas, p. 10. 
Llegué a Barranquilla en 1935, en pleno gobierno de López Pumarejo. También era la época del conflicto español que culminó en la Guerra civil con la invasión de Franco y de los alemanes y de los italianos contra la República Española. A todo ello me vinculé rápidamente. Así, en lo nacional me uní a la política de López Pumarejo y en lo internacional, a la lucha contra el fascismo. Fui, desde el punto político, lopista de toda la vida [...] Nos ayudó mucho un profesor de geografía que se inventó que su clase se hiciera con los periódicos del día. Entonces teníamos que leer noticias del mundo en el periódico y ubicar los países a los que se re refería las noticias. Así uno iba haciendo su propio mapa con base de la información de la prensa. Aprendimos geografía y cuestiones internacionales de manera impresionante ${ }^{17}$.

Luego de terminar su bachillerato en la Universidad de Cartagena, Apolinar continúa sus estudios de Derecho en la misma universidad ${ }^{18}$, fue ahí en donde empieza a poner en práctica su formación ideológica pero no solo sobre los problemas que enfrentaba la universidad, sino en las luchas agrarias de los pueblos del Caribe colombiano. De la universidad de Cartagena, Apolinar recuerda:

Porque aquí formé mi rebeldía, liberé mi estirpe revolucionaria, -no disminuida, por cierto, pese al paso de los años-; porque aquí, en sus salones y corredores, se templó mi espíritu como componente de una generación que emergió y se formó intelectualmente en esa confrontación tenaz y radical que fue la lucha contra el fascismo, al tiempo que fue marcada por la utopía y desafío del humanismo socialista [...] en la Universidad de Cartagena, la de Indias, se desarrolló y desenvolvió mi vocación para la solidaridad con los trabajadores y de apoyo a las luchas campesinas por la tierra, junto a las reivindicaciones propiamente universitarias y estudiantiles ${ }^{19}$.

$\mathrm{Y}$ en cuanto a su participación en las luchas agrarias en su tiempo de estudiante universitario, menciona:

Fui estudiante revolucionario porque participaba en las luchas sindicales siendo estudiante; era estudiante revolucionario porque participaba desde entonces en las luchas agrarias; estuve en varios pueblos de la costa en reuniones con campesinos, organizando campesino. [...] era un estudiante revolucionario que trabajaba en la lucha contra el fascismo y contra la derecha del mundo; esos marcos fueron los de mi trabajo en la universidad ${ }^{20}$.

En ese orden de ideas, no es extraño entonces que Apolinar reconociera que las dos experiencias que marcaron su vida para siempre, estarían asociada a su formación política y a la lucha por las transformaciones económicas y sociales a favor de las clases populares y campesinas: "La experiencia del 9

${ }^{17}$ I. Russi Urbano, El pasado, el presente y futuro visto por Apolinar Díaz Callejas, p. 13.

${ }^{18}$ Dora Piñeres de la Ossa, "Expresiones de proyección social de la universidad de Cartagena desde el desarrollo profesional de sus egresados: las humanidades, la economía, la política, la salud y la cultura en el Caribe colombiano, 1920-1946". La Cátedra Historia de la Universidad de Cartagena, 5, 2016: 47-48.

${ }^{19}$ Apolinar Díaz Callejas, "Mi universidad y la ciudad". Sociología, 21, 1998: 85.

${ }^{20}$ I. Russi Urbano, El pasado, el presente y futuro visto por Apolinar Díaz Callejas, p. 15. 
de abril de 1948 en Barrancabermeja y la participación intensa en el objetivo del doctor Lleras Restrepo de organizar al campesinado como herramientas de presión para lograr una reforma agraria son dos de mis importantes experiencias $^{21}$ "

\section{Vida profesional y la gobernación de Sucre}

Al terminar sus estudios de derecho, inicia su vida laboral con la Federación de Sindicatos del Río Magdalena, FEDENAL, luego trabaja con Diego Montaña Cuellar en la defensa de los dirigentes sindicales petroleros en Barrancabermeja, después fue miembro de la Federación de Arrocero, gerente de los molineros de arroz y gerente de la Sociedad de Agricultores de Colombia, SAC, estando en este cargo, fue cuando el presidente Carlos Lleras Restrepo (1966-1970) le ofrece el puesto de gobernador del recién creado departamento de Sucre. Aceptar el cargo para Apolinar fue una decisión complicada desde el punto de vista económico, pues el salario de gobernador era ínfimo en comparación con lo que ganaba en su mejor periodo de su vida profesional:

Yo en ese momento estaba en mi mejor periodo profesional. Un ministro ganaba seis mil quinientos pesos mensuales y yo, en ese momento, con el sueldo de la gerencia de la Sociedad de Agricultores que era seis mil, más varios contratos, uno que tenía con Bavaria en una asistencia jurídica y otros, recibía neto, mensualmente, dieciséis mil pesos [...] pero además de eso, me cayó un contrato compartido para la reclamación de impuesto de Bavaria que valía como quinientos y pico de millones de pesos ${ }^{22}$.

Hacer parte del gobierno de Carlos Lleras Restrepo era un honor, responsabilidad y compromiso para Apolinar, pues este gobierno con su lema "Transformación nacional", auguraba buenos resultados económicos y sociales, ya que tenía como meta principal una reforma económica y agraria para Colombia. Esto significaba que, desde la gobernación de Sucre, Apolinar tenía que mostrar efectividad y eficiencia en la implementación de las políticas de este gobierno, además mostrar "honradez y pulcritud en el manejo de la cosa Pública", como tal cual lo demostraría en lo sucesivo de sus once meses de gobernador (1967-1968):

Ser Gobernador de Sucre bajo el gobierno de Dr. Carlos Lleras Restrepo no era cualquier cosa y sí un hondo significado, porque si algo se le reconoce a Lleras es su honradez y pulcritud en el manejo de la cosa pública, actitud personal que exigía a todos los hombres y mujeres que pretendiera trabajar con él, y Díaz Callejas lo cumplió a cabalidad pues en su gestión no hubo despilfarro, robos y desorden o malversación de los fondos del Departamento, por el contrario, hubo eficiencia en todos los procesos administrativos desarrollados en esa época ${ }^{23}$.

${ }^{21}$ I. Russi Urbano, El pasado, el presente y futuro visto por Apolinar Díaz Callejas, p. 21.

${ }^{22}$ I. Russi Urbano, El pasado, el presente y futuro visto por Apolinar Díaz Callejas, pp. 26-27.

${ }^{23}$ B. Herazo Acuña, Semblanzas de hombres meritorios, p. 115. 
A pesar del dinero que dejaba de ganar por renunciar a todo sus contratos administrativos y legales, terminó Apolinar aceptado el cargo de gobernador de Sucre. Su reticencia al cargo se la expuso al presidente Lleras, quien vio en sus razones de no aceptar el cargo, más ventajas que desventajas, pues consideraba que Apolinar era la persona capaz de poner al fin a funcionar en el territorio la torpedeada reforma agraria del presidente Alberto Lleras Camargo (ley 35 de 1961), especialmente, en ese nuevo departamento, donde los terratenientes tenían el poder político:

Cuando fui nombrado gobernador del departamento de Sucre por el presidente Lleras Restrepo. Yo no quería ir, no acepté en un comienzo; pero me dijo "píenselo, por favor píenselo, y yo le dije: "si presidente, soy de por allá, pero de Sucre conozco Colosó, mi pueblo, y Sincelejo, la capital, nada más". Y me dijo: "No se preocupe que usted e un mes ya conoce todos los pueblos, yo lo conozco", al final le dije: "Mire presidente, hay otro argumento, yo me conozco, usted me conoce, usted sabe que yo soy un hombre de izquierda, yo creo en su proyecto de reforma agraria, por eso me gustaría ir; creo en su programa d organización campesina, creo en todo eso, pero eso supone lo siguiente: Sucre es un departamento política y económicamente de propiedad de siete grandes familias, yo no puedo ir a gobernar de acuerdo con el criterio de esas siete grandes familias acostumbradas, desde que vino al mundo, a que ellas no las gobiernan, ahí hay incompatibilidad que va hacer que eso no sea posible". Entonces me dijo: "No hay que temer, es que yo lo nombro gobernador y quiero se vaya de una vez es para enfrentar a esa gente". El programa de organización campesina no se había podido poner en marcha y esa era la clave de la reforma agraria. Este programa no lo entendía nadie, hasta lo combatió la izquierda pues dijo que era una maniobra del sistema. Pues bueno, el caso esa carta blanca la usé inmediatamente. Al mes de estar allá, tal cual como él dijo, había recorrido todo el departamento de Sucre. Me lleve a los funcionarios del Ministerio de Agricultura encargados de la organización campesina a organizar asociaciones de usuarios campesinos en todos los municipios, y yo, como gobernador, iba y presidía las reuniones con el apoyo de la autoridad, la policía y los campesinos. Los terratenientes temblaban ${ }^{24}$.

"La carta blanca" de apoyo que le había dado el presidente Lleras a Apolinar, le permitió gobernar sin cortapisas e intromisiones de los líderes políticos de los partidos tradicionales del departamento. De modo, que empezó implementando en el departamento la reforma agraria, en especial, las organizaciones campesinas, a través de la Asociación de Usuarios Campesino, $\mathrm{ANUC}^{25}$, bajo los parámetros legales establecidos por la ley. Sin embargo, no dejó de ser molestoso y provocar animadversión contra él en los grandes latifundistas, y popularidad en las organizaciones campesinas y

\footnotetext{
${ }^{24}$ I. Russi Urbano, El pasado, el presente y futuro visto por Apolinar Díaz Callejas, pp. 32-33.

${ }^{25}$ La Asociación Nacional de Usuarios Campesinos de Colombia, ANUC, fue creada de conformidad con la ley 975 de 1967 que dispuso la creación de la ANUC, el decreto 755 del 2 de mayo de 1967 y la resolución 061 de 1968, obtuvo su personería jurídica mediante la resolución 649 del 30 de julio de 1970 expedida por el Ministerio de Agricultura; durante el gobierno de Carlos Lleras Restrepo. A través de esta ley se transformó la mentalidad del campesino. Se inicia la ruptura de los campesinos con la condición de sirvientes de los propietarios de las tierras, en formuladores de propuestas políticas para su bienestar general y luchar de forma organizada. El departamento de Sucre fue piloto para trabajar directamente con la masa campesina durante 3 meses, para ello, fueron enviados los primeros formadores en organizarlas y formarlas.
} 
en sus bases. De este modo evoca Apolinar esos primeros meses de su gobierno:

Te voy a contar el primer caso que tuve como gobernador. Mi secretario de gobierno era conservador, tenía que ser por eso era la paridad. Conseguí entonces de secretario de a u eminentísimo médico conservador de Corozal, el doctor Luís Taboada de Vivero, gran señor, medio filósofo. Resulta que empezó todo lo de la organización campesina, cuando hubo una invasión de fincas en Corozal, a quince o veinte minutos de Sincelejo. Las fincas eran de las tías de mi secretario de gobierno, y me dice "Gobernador, le traigo una mala noticia. Anoche los campesinos de Los Palmitos invadieron la finca de mis tías y lo peor es que dicen que usted los mandó". Y le dije: "Bueno, doctor Licho, primero aclaremos una cosa ¿usted cree que yo mandé a esos campesinos a invadir la finca de sus tías?", me dijo: "No, nunca, sé que usted no lo ha hecho, de eso no se preocupe, pero es lo que dicen, con eso lograron que cuando llegó la policía a desalojarlos, no se atrevieran a sacarlos, porque estaban por cuenta suya". Hablamos mucho, le hice ver que como Secretario de Gobierno, debía responder por el orden público así que le di todo mi respaldo para que hiciera lo conveniente. Le di absoluta libertad de acción y de dije: "Haga lo que le parezca, si usted cree que ellos no son campesinos sino unos bandidos que quieren ocupar tierras ajenas y que hay que meterle la policía, métale la policía, yo respaldo todo lo que usted haga." Y me respondió: "Pero gobernador yo solo no voy a poder resolver eso". Total que discutimos un poco y le dije que, puesto que yo representaba a un gobierno como el del doctor Lleras Restrepo que impulsaba la reforma agraria, debía resolver las cosas bajo de ese marco ideológico, siguiendo las políticas del presidente Lleras. Entonces llamé al doctor Lleras Restrepo, le eché el cuento, estaba feliz de que al fin se había armado el choque sobre la cuestión de la reforma agraria en Sucre, y le pedí que me mandara en un avión el INCORA. Me dijo que a primera hora del día siguiente me lo mandaba. Los terratenientes no habían permitido que existiera ni siquiera oficina del INCORA en Sucre; estamos hablando de 1967 y el INCORA existía desde 1961. Les dije que los iba a instalar en cualquier cuarto de la gobernación, para que se pusiera al frente del problema. Me dijo entonces el secretario, el doctor Licho: "Yo estoy de acuerdo con usted, yo no mando a matar campesino, de manera que yo apoyo lo usted considere". Y bueno, llegó el INCORA, negociaron con las tías y los campesinos. Muchas de esas tierras quedó al final en manos de campesinos. Se sentó el precedente de que invadiendo se conseguí tierra, y comienza una avalancha de invasiones de tierra... ¡Carajo! A mi a veces me daba pena...y esa gente no me aguantaba, por supuesto. ${ }^{26}$

\section{Los caminos de agua y las aguas blancas}

En su periodo de gobernador de este recién creado departamento (el primer gobernador demoró cuatro meses en el cargo), inició Apolinar enfrentando una dura situación que se venía presentado desde hacía treinta años en la olvidada región de la Mojana, y no había desde entonces ningún gobernador de Bolívar que hubiese enfrentado las inundaciones constante de los

\footnotetext{
${ }^{26}$ I. Russi Urbano, El pasado, el presente y futuro visto por Apolinar Díaz Callejas, pp. 33-34.
} 
municipios del sur de Sucre (San Marcos, San Benito Abad, Majagual, Sucre y Guaranda), que antiguamente pertenecían al departamento de Bolívar.

A finales del siglo XIX el caño Mojana comenzó a perder la boca por donde alimentaba su caudal del río Cauca. La sedimentación producida en parte por la explotación de las minas de aluvionales de la región de Nechí y en parte por fenómeno de la erosión causada por la deforestación de las riberas del Cauca.

Esto produjo de manera lenta el taponamiento de la boca, privando a las poblaciones de Majagual y Sucre ubicadas en sus márgenes, de agua y, por supuesto, de la navegación. Ante esta calamidad, los mojaneros trataron de abrir otras "bocas" por donde el Cauca alimentara el caudal de su caño, sin resultados positivos, como fue el caso de la rehabilitación del caño del "Cachimbero", ubicado cerca de Guaranda, que fue fracaso total por la alta concentración de sedimento que arrojaba el Cauca ${ }^{27}$.

Para los años treinta, el caño Mojana estaba prácticamente incomunicado con el río Cauca, produciendo este hecho graves calamidades para el comercio y la salud de la población (causando enfermedades paludismo, disentería, tifo y anemia tropical, producidas por el estancamiento de las aguas). Ante esta situación en el año 1936, ante la alarmante emergencia sanitaria que venía ocasionando el secamiento del caño Mojana el padre José Gavaldá Sales ${ }^{28}$, sacerdote del seminario de Burgos, España, quien hacía parte de vicariato apostólico del San Jorge y la Mojana, convocó a feligresía de Majagual para iniciar una campaña pro-construcción del canal de Morrohermoso, como única salida al problema sanitario, esta fue terminada e inaugurada en 1938. Esta obra permitió el establecimiento de la navegación fluvial por el caño Mojana, haciendo florecer el comercio del municipio de Majagual ${ }^{29}$.

No obstante, mientras Majagual prosperaba, Achí y Sucre se opacaban. La apertura del canal de Morrohermoso produjo grandes daños para el sector agrícola regional, especialmente para el sector cultivador de caña de azúcar. Las aguas del río Cauca fueron convirtiendo poco a poco el pequeño canal en un caudaloso brazo. Como consecuencia de este fenómeno, la región comenzó a sufrir periódicas inundaciones que terminaron de arruinar los extensos cañaduzales, cuya planta es muy sensible al exceso de humedad. Cientos de plantíos quedaron bajo el manto de las aguas del Mojana y con ello parte de la exitosa industria panelera. Las tierras bajas de Sucre fueron sepultadas por millones de litros de agua que cubrían la superficie hasta por siete meses del año ${ }^{30}$. Frente al desastre natural provocado por la "Boca del Cura" -nombre con el cual se conoció el canal de Morrohermoso-, los comerciantes e industriales de Sucre, quienes resultaron ser los más

\footnotetext{
${ }^{27}$ Bernardo Ramírez y Edgar Rey Sinning, La Mojana: Poblamiento, producción y conflicto social, Cartagena, Costa Norte Editores Colombia Ltda, 1994, p. 111.

${ }^{28}$ El sacerdote José Gavaldá Sales, perteneciente al Vicariato Apostólico de San Jorge, regido por los misioneros de Burgos, España, quien había realizado estudios de ingeniería, fue el que dirigió la construcción del canal de Morrohermoso, y, asimismo, dirigir las construcciones de algunas iglesias de la Mojana.

${ }^{29}$ B. Ramírez y E. Rey Sinning, La Mojana: Poblamiento, producción y conflicto social, p. 113

${ }^{30}$ B. Ramírez y E. Rey Sinning, La Mojana: Poblamiento, producción y conflicto social, p. 122.
} 
perjudicados, comenzaron a ejercer toda clase de presiones ante el gobierno nacional y departamental para lograr el cerramiento del canal. De esta manera, le es enviado al nuevo gobernador este comunicado:

Sucre, Sucre. Abril 18 de 1968. URGENTE. Doctor Apolinar Díaz Callejas. Gobernador Departamento. Sincelejo. Infórmole barrejobo en el río Cauca rompió parte obras para tapar la Boca del Cura, comenzando inundación, pues Cauca se metió nuevamente por ahí. El agua ya viene por Palmarito. Urge su ayuda. Atentamente. Carmelo Sáenz Jorge, Alcalde ${ }^{31}$.

Los conocimientos que hasta entonces Apolinar tenía de la Mojana eran producto de sus lecturas de libros y estudios económicos y sociales de esta región. Así fue que atendiendo este llamado de los alcaldes y líderes cívicos de estos municipios, es que decide hacer su primera visita como gobernador a esta región. Su gestión oportuna con gobierno nacional, departamental y el comité cívico local, encabezado por la clase pudiente de Majagual, logran el propósito de cerrar definitivamente la Boca del Cura en 1968; no obstante, estos esfuerzos fueron demasiado tarde, pues ya la industria panelera había prácticamente desaparecido y los cultivos de caña se habían reemplazado por los del arroz ${ }^{32}$.

Los municipios del bajo San Jorge y Mojana nunca en su historia habían tenido la visita de un gobernador, ni menos de Bolívar cuando estos pertenecían a este departamento, pues la distancia de Cartagena a la Mojana era de días enteros, en cual para transportarse era una verdadera odisea, ya que se tenía que hacer un recorrido en carros, lanchas, canos y en animales, como caballos y burros para llegar a los lugares más recónditos de la Mojana. Estos gobiernos de "control remoto" funcionaban a través del caciquismo político ${ }^{33}$, que engranaba lo local y lo regional a partir de cargos burocráticos, contratos, becas, dinero y favores políticos, de manera, que esta red, evitaba que los gobernantes o candidatos a cargos públicos se trasladaran a lugares distantes, para qué hacer presencia cuando con su red lo podían hacer.

\begin{abstract}
Antes los políticos solo se sentía obligados a mandar la plata a los gamonales para la compra de los votos y conseguir los nombramientos de maestras y maestros en las personas de sus familiares y de los gamonales más pequeños de los caseríos y veredas, no importa que apenas hubieran cursado primero o segundo año de primaria. Lo importante no es que sepan y puedan enseñar a los niños. Esa son precauciones de "demagogos" y "agitadores subversivos". Lo que vale es que ponga los votos [...] En esta
\end{abstract}

\footnotetext{
${ }^{31}$ Apolinar Díaz Callejas, Del agua y de hombre, Bogotá, Imprenta Nacional, 1976, p. 5.

${ }^{32}$ B. Ramírez del Valle y E. Rey Sinning, La Mojana: Poblamiento, producción y conflicto social, p. 123

33 "El caciquismo o patronazgo estaba ligado ante todo con las condiciones de atraso generalizado en la sociedad, vinculadas con una organización precapitalista, en la cual las relaciones mercantiles eran incipientes, la urbanización estaba definida por comunidades pequeñas y personalizadas, la disponibilidad de bienes era limitada y el Estado tenía una cobertura ínfima. En tal situación, el caciquismo constituía un recurso extendido, como compensación a la insuficiencia en la satisfacción institucionalizada de necesidades [...] [entre el clientelismo] hay una diferencia fundamental con respecto al caciquismo. Se trata de la ingerencia creciente que tiene el Estado en el proceso [...] la utilización de recursos oficiales para implementar las relaciones políticas de clientela constituye un aspecto central de la mediación estatal y, por tanto, del carácter moderno, nuevo, del fenómeno." Cita tomada del libro. Francisco Leal Buitrago y Andrés Dávila L. Clientelismo. El Sistema Político y su Expresión Regional, Bogotá, Tercer Mundo, 1990, pp. 43-44.
} 
forma se asegura la votación para el "jefe", el que manda la plata o los tubos para unos acueductos que no se construyen, y quien generalmente es un gran latifundista a alguien a su servicio ${ }^{34}$.

De este modo, muchas regiones con sus lamentables problemáticas económicas y sociales fueron quedando cada vez más olvidada. Por consiguiente, para la gente del sur de Sucre resultaba extraño las visitas del recién nombrado gobernador de Sucre, Apolinar Díaz Callejas:

Al fin un gobernador visitaba a los pueblos, hablaba con las gentes, oía los problemas y las peticiones. Que eran los mismos: Vías, escuelas, buenos maestros, puesto de salud, un médico, el puente sobre el arroyo grande Corozal, radioteléfono, un pozo de agua potable, la inspección de policía. Era lo que pedían. Así lo hicieron los padres, y los padres de los padres, y los padres de los padres de los padres. Hasta llegar a Bolívar mismo. Se acuerda de eso desde cuando estaba chiquito.

Cipriano Ricardo en Majagual "Tal vez ahora se pueda. Cuando ya ha visto a un gobernador. Creía que era diferente. Pero es igual a los demás hombres. [...] "Por eso he venido, para decirle que nos visite". "También nosotros somos gente, y hasta colombiano ${ }^{35}$.

Luego de cerrada la Boca del Cura con la participación de los gobiernos nacional y departamental, y de la junta cívica local, en donde se recuperaron una considerada cantidad de hectáreas de tierra inundadas, Apolinar descubre que los beneficiarios fueron un pequeño un grupo terratenientes, esta situación justificaba una reforma agraria integral en la Mojana, como la estaba proponiendo el gobierno de Lleras Restrepo, finalmente esta propuesta quedó inconclusa con el freno de la contrarreforma agraria sellada con el Pacto de Chicoral $^{36}$, durante el gobierno de Misael Pastrana Borrero.

De lo contrario, ocurriría lo mismo que cuando fue cerrada la Boca del Cura, en Majagual, Sucre, durante la administración Lleras Restrepo, que permitió recuperar de inundaciones aproximadamente 2.000 hectáreas de tierra y mejorar notablemente otras 25.000 , pero en que los beneficios solo llegaron a un minúsculo grupo de grandes terratenientes, porque después fue abandonada la reforma agraria como programa, para convertirla en el plan de parcelaciones y colonización

Otro aspecto trascendental para San Jorge y La Mojana sucreña que intentó recuperar e implementar en su rol de gobernador de Sucre, fue la

\footnotetext{
${ }^{34}$ A. Díaz Callejas, Del agua y de hombre, pp. 9-10.

35 A. Díaz Callejas, Del agua y de hombre, p. 200.

${ }^{36}$ El 9 de enero de 1972, bajo el gobierno de Pastrana Borrero, se firmó entre los partidos tradicionales y los gremios de propietarios el Pacto de Chicoral que puso fin a la reforma agraria. Ahora, el gobierno consideraba que la organización campesina era subversiva y tomó todo tipo de medidas para restar influencia a la Asociación Nacional de Usuarios Campesinos (ANUC), creada por inspiración del propio Lleras Restrepo a través de la Ley 1a. de 1968. El senador Hugo Escobar Sierra denunció en el Congreso las invasiones de tierras y afirmó que la movilización campesina era alentada por el terrorismo internacional y el comunismo. El gobierno de Pastrana convocó a las fuerzas políticas, a los ganaderos, arroceros y bananeros y a los latifundistas. Vásquez citado por Albán, menciona que: "Los términos del Pacto de Chicoral fueron suficientemente claros en su intención de emprender formalmente la contrarreforma agraria. A cambio del pago de impuestos al Estado, fijado de acuerdo a una renta presuntiva cuya referencia principal sería el avalúo catastral de los predios, los terratenientes recibían amplias garantías de que se pondría freno a la redistribución de la tierra y se apoyaría la explotación agrícola en gran escala". Alvaro Albán, "Reforma y contrarreforma agraria en Colombia". Revista de Economía Institucional, 13, (24), 2011: 348.
} 
intercomunicación fluvial y la navegabilidad entre ríos, caños y ciénagas de estas regiones, de manera que solicitó al director del Fondo de Caminos Vecinales ampliar sus actividades en la incorporación de estos sistemas de caños y canales, pues consideraba Apolinar, que es:

tan camino vecinal es el terrestre como acuático propio de este delta, a fin de integrarlos, limpiarlos, profundizarlos cuando se requiera e intercomunicarlos, creando una red de transporte fluvial en tan inmensa región, que permitiría viajar en los inviernos desde San Marcos a Majagual o Sucre y demás poblaciones, pasando por el caño Rabón, en embarcaciones livianas. Es un don de la naturaleza no aprovechado ${ }^{37}$.

Por otro lado, en el plano de la política departamental articulada con la nacional, la animadversión contra Apolinar de los latifundistas y de los líderes políticos de los partidos liberal y conservador, nunca cesaron durante su gobierno; especialmente, en lo concerniente a la implementación de la reforma agraria, y la no participación de sus líderes en la burocracia departamental. Estos conflictos terminaron sacando del cargo a Apolinar, pues las recurrentes quejas al presidente Lleras se fueron poniendo incontrolables, más cuando, el mismo presidente se oponía a destituirlo del cargo. Sin embargo, estas quejas fueron llegando a la Dirección General del Partido Liberal, haciendo que ésta pidiera la cabeza del gobernador, alegando que el gobernador "había organizado en Sucre una revolución comunista ${ }^{38 "}$. Finalmente, el presidente Lleras Restrepo terminó cediendo a las pretensiones y pidiendo la renuncia de Apolinar. Y no solo eso, sino "Lo convencieron [presidente Lleras] los mismos que le pidieron que me sacara a mí de la gobernación, de que no debía seguir hablando de reforma agraria" ${ }^{39}$. Luego de su renuncia al cargo de gobernador, el presidente Lleras Restrepo lo nombra Viceministro de agricultura, donde muchas veces fungió como ministro encargado en esa cartera. Pero el cambio de discurso del presidente con relación a la reforma agraria fue cambiando por presiones de los partidos políticos y los latifundistas, esto hizo que Apolinar renunciara al Ministerio y continuar su "batalla política a los terratenientes ${ }^{40 "}$ en el Senado de la República.

\section{EI Senado y la Misión Colombo-Holandesa ${ }^{41}$}

Así fue que en 1970 llegó al Senado de la República por un sector progresista del liberalismo y se hizo sentir por sus intervenciones elocuentes,

\footnotetext{
${ }^{37}$ A. Díaz Callejas, Del agua y de hombre, p. 154.

${ }^{38}$ I. Russi Urbano, El pasado, el presente y futuro visto por Apolinar Díaz Callejas, p. 25.

${ }^{39}$ I. Russi Urbano, El pasado, el presente y futuro visto por Apolinar Díaz Callejas, p. 37.

${ }^{40}$ I. Russi Urbano, El pasado, el presente y futuro visto por Apolinar Díaz Callejas, p. 36.

${ }^{41}$ El estudio de la Misión Colombo-Holandesa abarcaban los campos de la navegación fluvial; protección a las ciudades y poblaciones menores contra las inundaciones; desarrollo agropecuario de cuenca mediante la ejecución de obras para el control de inundaciones y para la dotación de riego y sistemas de drenaje donde ello es viable al corto, mediano y largo plazo; generación de energía eléctrica, aprovechando las caídas de agua, saltos y embalses técnicamente aprovechable, tanto de los ríos Cauca y Magdalena como de sus afluentes; suministro de agua para uso humano e industrial; desenvolvimiento de la pesca en ríos y ciénagas de la cuenca; aprovechamiento turístico no solo de río Magdalena sino del conjunto de los recursos de agua incorporados a la cuenca, así como de la caza deportiva.. Del agua y de hombre. A. Díaz Callejas, Del agua y de hombre, p. 26.
} 
comprometidas y valientes denunciando la reversión de los avances agrarios por el Gobierno de Pastrana Borrero, defendiendo las luchas de indígenas, obreros y campesinos, fustigando la injusticia como causal de la violencia y la pobreza, señalando culpables de la masacre de Vitoncó y planteando soluciones para la región del San Jorge y la Mojana sucreña ${ }^{42}$.

En su periodo de senador Apolinar siempre tuvo la fe puesta en la redención de los municipios de Sucre y Bolívar con la ejecución de los proyectos de la Misión Colombo-holandesa para la regulación fluvial y defensa contra las inundaciones de la Cuenca Magdalena-Cauca, en donde planteó la construcción de obras de ingeniería para controlar las inundaciones y recuperar las tierras. En lo referente al departamento de Sucre la Misión Colombo-Holandesa, proyectó la necesidad imperiosa de otras obras complementarias, tales como la construcción de las carreteras San MarcosMajagual, Achí-Majagual, Majagual-Sucre, y toda una telaraña de vías internas; así mismo, la construcción e instalación de bodegas y plantas de secamiento por parte del IDEMA, para el tratamiento y la comercialización de granos ${ }^{43}$. Sin embargo, sus esfuerzos en el congreso fueron insuficiente para la lograr la ejecución de los proyectos, y más, sin la voluntad firme del gobierno de turno para emprenderlos.

La falta de información política de nuestro pueblo, en cuanto al funcionamiento de las instituciones, lo llevan a pensar que un Senador puede definir las obras que se deben ejecutar. No saben que lo más que podemos hacer es solicitarle al Gobierno que las haga, o hacer un debate para pedir lo mismo en forma pública, en el recinto del Senado, o en una comisión constitucional. O sea, hablar en Congreso y ante los funcionarios. Hasta ahí llega nuestras posibilidades. Si el Gobierno no las quiere hacer, ni el Senado todo, y menos un Senador, puede obligarlo a construir esas obras. Esta clase de determinaciones solo el gobierno las puede tomar ${ }^{44}$.

Uno de los argumentos más fuerte de Apolinar para defender los proyectos de la Misión Colombo-Holandesa en el Senado, es que vislumbraba los conflictos futuros sobre la tenencia de la tierra que se podían suceder debido a los procesos naturales de sedimentación de las ciénagas, caños y del cambio de curso del río San Jorge, esto generaba el fenómeno de la accesión ${ }^{45}$, el cual desataría conflictos jurídicos de propiedad entre latifundista ganaderos y pequeños agricultores y pescadores ${ }^{46}$. De manera que llamaba la atención en el senado sobre esta problemática.

\footnotetext{
${ }^{42}$ G. Segovia, Las batallas de Apolinar.

43 A. Díaz Callejas, Del agua y de hombre, p. 21.

${ }^{44}$ A. Díaz Callejas, Del agua y de hombre, p. 22.

${ }^{45}$ El Código Civil en su artículo 713 define: "La accesión es un modo de adquirir por el cual el dueño de una cosa pasa a serlo de lo que ello produce o de lo que se adjunta a ella". De acuerdo a Velásquez: "el código enuncia dos clases de accesión: cuando una cosa se junta a otra, y la que se refiere a los frutos derivados de una cosa. La primera, considerada como verdadera accesión, y la segunda denominada así por el código pero que no obedece a la realidad del fenómeno jurídico y que la doctrina considera como simple extensión del derecho real de propiedad [...] La verdadera accesión es entonces la continua o por unión propiamente tal, que implica la unión de dos o más cosas de diferentes dueños y que forman un todo inseparable o indivisible. Si la cosa se puede separar sin detrimento del todo o sin que este desmerezca su valor, la accesión no se presenta [...] Clases de accesión continua: a. De inmueble a inmueble (aluvión, avulsión, mutación del cauce o álveo, formación de islas)", Luis Guillermo Velásquez, Bienes, Bogotá, Temis, 2000, pp. 259-260.

${ }^{46}$ Ver: Alejandro Camargo. Nuevas tierras que nacen del agua: una ecología política de la propiedad en las llanuras de Caribe Colombiano, Bogotá, Tesis para optar el título de magíster en geografía Universidad de los Andes, 2010; y Carlos
} 
El informe de la Misión es sobre la estructura actual de la tenencia de la tierra en relación a los títulos de propiedad, sin perjuicio de que esta sea una situación que tienda a modificarse en la medida en se producen fenómenos de accesión y otros fenómenos de apropiación de zonas que, especialmente en la región del San Jorge, fueron comunales. Incluso hoy, se mantienen todavía, se conservan todavía.

No ha llegado el alambre de púas a posesionarse de la totalidad de estos playones comunales, que los ganaderos, especialmente de las sabanas de Bolívar y de Sucre, movilizan sus ganados en las épocas de sequía en la parte de las sabanas para aprovechar un poco los pastos de estas zonas húmedas.

Entonces, se producen estos fenómenos de accesión y hay multitud de conflictos permanentes, particularmente no sobre la región del Cauca en donde hay una definición de la propiedad, sino especialmente para la región del San Jorge, donde se producen no solamente fenómenos de accesión sino que los cambios del cauce de los ríos y, por consiguiente, la movilización de las aguas hacia otras zonas, se van produciendo estos fenómenos de accesión.

Además, hay otra situación que es la de que en algunas zonas del San Jorge, en la medida en que río (que cambió totalmente de cauce, que desapareció su cauce antiguo. Yo estuve visitando el viejo lecho del río San Jorge, por el cual, incluso, se transportaba ganado, donde hoy no queda sino un triste arroyo que se puede cruzar a pie con el agua apenas hasta las rodillas), por los fenómenos de sedimentación produce un hecho que es el de que hay propietarios que tienen finca en medio de la zona y en que en la medida que se van sedimentando, van quedando como de propiedad de ellos.

Pero el problema es que estructura de la tenencia de la tierra a que me he referido está ligado a la tierra titulada o no, a estos otros fenómenos que se representan indudablemente y que dará lugar también a problemas jurídicos, en cuanto la circunstancia de la accesión constituye un título para el propietario beneficiado con este fenómeno de la naturaleza ${ }^{47}$.

\section{Campaña de un político raro y la unidad de los pobres}

La campaña política que realizaba Apolinar era totalmente diferente a las de los políticos tradicionales, pues él recorría palmo a palmo las subregiones de Sucre en diferentes épocas del año, tanto en periodos de sequía e inundaciones; ya que no contaba ni tampoco deseaba hacerlo, contar con la ayuda del clientelismo político, supeditado al dinero, a la burocracia y cambio de favores por votos. Por consiguiente, su campaña era de un político pobre, que se soportaba en la escucha de las necesidades de la gente y en el discurso:

En la campaña de político pobre. Echando lengua y gastando saliva. Una campaña de pueblo en pueblo, vereda en vereda, de monte en monte. Hay que saludar y conocer a la gente. Los otros mandan la plata, mucha plata, y tubos de acueducto. Uno no puede. Solo palabra y saliva, para llegar un poco a la consciencia. Y levantarla. Lograr que se subleven. Lo cual ocurrirá, "más temprano que tarde", como decía Allende. Aun cuando no haya votos ahora. Pero se sublevarán contra la resignación y el destino que

Cadrasco Martelo, "San Benito Abad: el municipio en donde la tierra es de todos y es de nadie", en https://semanarural.com/web/articulo/campesinos-y-ganaderos-de-san-benito-abab-tienen-disputas-por-tierras/929

47 Apolinar Díaz Callejas, Sobre la Mojana, Bogotá, CLAC-Impresores Editores, 1978, pp. 67-69. 
el sistema le ha señalado. Al fin y al cabo, el destino de los pobres, no es sino el que le han asignado las clases que mandan, que tienen el poder. Por eso, las clases, cambiará el destino ${ }^{48}$.

Las condiciones lamentables de pobreza y abandono que sufrían los corregimientos, veredas y caseríos de la Mojana después de las inundaciones, no lo dejaba muchas veces hablar a Apolinar del tema electoral, por el pudor y la vergüenza que lo embargaba por el estado desolación en que se encontraban, solo le permitía escuchar y observar, lo que en ojos de muchos habitantes de esta región, lo vieran como un "político raro". De esta forma cuenta Apolinar su recorrido de campaña en el corregimiento de la Ceja y el caserío de las Tarullas, de Guaranda, después que estos padecieran de una fuerte y larga inundación:

Yo escondo el tema electoral. [...] En la conversación van soltando a pedacito su realidad, su verdad: no han tenido escuela, nunca ha habido maestro, no hay puesto de salud, no conocen un médico, no hay un pozo de agua potable, no hay iglesia, ni cura, ni autoridad, ni inspección de policía, ni cárcel, ni botica, ni energía eléctrica, ni teléfono, ni siquiera palomas mensajeras para avisar que están muriendo. Nada. No tienen nada de nada. Solo crecientes, inundaciones, desolación y cadáveres de cosas, cadáveres de cosas, cadáveres de pobres de gentes pobres.

Nos despedimos para reanudar la marcha hacia LAS TARRULLAS. Hay más cordialidad. Menos desgano.

Yo observo una cierta perplejidad en ellos. No me queda difícil imaginarme la causa. Hablamos de muchas cosas, de sus miserias y necesidades, de las crecientes, de las inundaciones, de los cadáveres de cosas pobres de gentes pobres, de los alambres del latifundio -que caminan y los cercan y despojan de lo divino y de lo humano. De todo.

De algo no hablamos: de política y de votos. Un profundo sentimiento de pudor y vergüenza me impedía tocar esos temas. Y no lo hice.

Esa era su perplejidad: "Qué político tan raro", debieron de comentar después de nuestra partida. "anda en campaña política y electoral y no habla de política ni pide votos", pudo ser lo que me dijeron después que nos marchamos ${ }^{49}$.

Sin embargo, a pesar del panorama de pobreza y desolación de los municipios del San Jorge y la Mojana sucreña en ese entonces, Apolinar albergaba la esperanza que tarde o temprano, "la unión de los pobres" en ese territorio podían cambiar esta situación, pues solo ellos desde abajo y juntos serían los únicos que lo podrían hacer:

Sin embargo, creo que algunos comenzarán a entender el significado de frases aisladas que solté como quien no quiere la cosa: "la unidad de los pobres", ya pasó la época de los milagros, ahora el milagro lo hace la unidad de los pobres"; "la única fuerza que tienen los pobres es su unidad" [...] Algún día comprenderán que de arriba no llegará la solución. Este es

${ }^{48}$ A. Díaz Callejas, Sobre la Mojana, p. 202

${ }^{49}$ A. Díaz Callejas, Sobre la Mojana, p. 123 
un problema de los de abajo, para los de abajo, y que solo resolverán los de abajo ${ }^{50}$.

\section{Conclusión}

Apolinar Díaz Callejas fue indiscutiblemente un político atípico de los que no se acostumbra a ver en el país, pues esa mezcla entre su acción política como defensor de sindicalistas, luego, de gobernador, viceministro de agricultura y senador, y su destacado trabajo intelectual de historia local y regional, y del derecho internacional en Colombia, hace cada vez más importante su legado. De igual modo, su trabajo intelectual y político iban de la mano, pues para él no era suficiente comprender un departamento como el de Sucre ni regiones como la del San Jorge y Mojana, sino se aportaba a la transformación política, económica y social de territorio, pero no a través de la cooptación política, sino desde la "unión de los pobre", en donde el intelectual solo es un mediador para hacer conciencia política e incentivar las luchas por las transformaciones, pero, en Apolinar desde la institucionalidad o hasta donde el sistema político lo permitiera, pues siempre se consideraría un socialdemócrata.

\section{Referencias}

Albán, Álvaro, Reforma y contrarreforma agraria en Colombia. Revista de Economía Institucional, 13, (24), 2011.

Cadrasco Martelo, Carlos, "San Benito Abad: el municipio en donde la tierra es de todos y es de nadie", en https://semanarural.com/web/articulo/campesinos-y-ganaderos-desan-benito-abab-tienen-disputas-por-tierras/929

Camargo, Alejandro. Nuevas tierras que nacen del agua: una ecología política de la propiedad en las llanuras de Caribe Colombiano, Bogotá, Tesis para optar el título de magíster en geografía Universidad de los Andes, 2010.

Leal Buitrago, Francisco y Dávila L., Andrés, El Clientelismo. El Sistema Político y su Expresión Regional, Bogotá, Tercer mundo editores. 1990.

Díaz Callejas, Apolinar, "Baltazar Pérez: Precursor del Recurso de Tutela", en Apolinar Díaz Callejas, Ensayos, Narraciones y Crónicas de Colosó, Bogotá, Plaza Impresores, 1998.

Díaz Callejas, Apolinar, "Rosa Luisa Uribarren". Crónicas de Colosó, Apolinar Díaz Callejas, Ensayos, Narraciones y Crónicas de Colosó, Bogotá, Plaza Impresores, 1998.

Díaz Callejas, Apolinar, De la situación de la nación y del partido liberal, Bogotá, CLAC Impresores Editores, 1977.

Díaz Callejas, Apolinar, Del agua y de hombre, Bogotá, Imprenta Nacional, 1976.

${ }^{50}$ A. Díaz Callejas, Sobre la Mojana, pp. 123-124 y 127. 
Díaz Callejas, Apolinar, “Mi universidad y la ciudad”. Sociología, 21. 1998.

Díaz Callejas, Apolinar, Sobre la Mojana, Bogotá, CLAC-Impresores Editores. 1978.

El Espectador. La lista de "sentenciados por las FF.MM" hallada en el bolsillo de Héctor Abad Gómez. https://www.elespectador.com/judicial/la-lista-de-sentenciados-porlas-ffmm-hallada-en-el-bolsillo-de-hector-abad-gomez-article-868962/

Fals Borda, Orlando, Campesinos de los Andes, Bogotá, Editorial Iqueima. 1961.

Herazo Acuña, Benjamín, Semblanzas de hombres meritorios, Bogotá, Ediciones Ecoe, 1994.

Márceles Daconte, Eduardo, "Cien años de Héctor Rojas Herazo", en El Magazín Cultural El Espectador. https://www.elespectador.com/el-magazin-cultural/cienanos-de-hector-rojas-herazo/

Piñeres de la Ossa, Dora, "Expresiones de proyección social de la universidad de Cartagena desde el desarrollo profesional de sus egresados: las humanidades, la economía, la política, la salud y la cultura en el Caribe colombiano, 1920- 1946". La Cátedra Historia de la Universidad de Cartagena, 5, 2016.

Ramírez, Bernardo y Rey Sinning, Edgar, La Mojana: Poblamiento, producción y conflicto social. Cartagena, Costa Norte Editores Colombia Ltda, 1994.

Russi Urbano, Ivanov, El pasado, el presente y futuro visto por Apolinar Díaz Callejas, Bogotá, Editorial Gente Nueva, 2003.

Segovia Mora, Guillermo, Las batallas de Apolinar. 18 de agosto de 2010. En: https://rebelion.org/las-batallas-de-apolinar/

Velásquez, Luis Guillermo. Bienes, Bogotá, Temis, 2000. 